\title{
Small-for-Size versus Standard-Size Graft in Living Donor Liver Transplantation
}

\author{
Abdul Wahab Dogar, Shams Uddin, Azhar Hussain, Kaleem Ullah, Abdul Ghaffar and Syed Hasnain Abbas \\ Department of Liver Transplant Unit, Pir Abdul Qadir Shah Jeelani Institute of Medical Sciences, Gambat, Sindh, Pakistan
}

\begin{abstract}
Objective: To compare the outcome of small-for-size grafts versus standard-size grafts regarding the frequency of postoperative complications, early graft dysfunction, and 1-year survival.

Study Design: Retrospective cohort study.

Place and Duration of Study: Pir Abdul Qadir Shah Jeelani Institute of Medical Sciences (PAQSJIMS) Hospital, Gambat, Sindh, Pakistan from March 2019 to April 2020.

Methodology: A total of 147 living donor liver transplant recipients' data were retrospectively evaluated. Study participants were divided into two groups; small-for-size graft (GRWR $<0.8 \%$ ) and standard-size graft (GRWR $\geq 0.8 \%$ ). Recipients' demographics, graft characteristics, operative parameters, postoperative complications, and graft survival were compared in both groups.

Results: Out of 147 recipients, 21 were found to have small-for-size graft, while 126 patients had the standard-size graft. Mean GRWR in small-for-size graft group was $0.73 \pm 0.4(0.63-0.79)$, while $0.93 \pm 0.82(0.81-3.0)$ in standard-size graft group. A statistically significant difference was found while comparing body mass index $(p<0.001)$, hepatic venous reconstruction $(p=$ $0.013)$, and liver attenuation index $(p<0.001)$ between both study groups. While all other recipient and donor characteristics, demographical data, operative variables, postoperative lab, and complications were comparable in both groups $(p>0.05)$. Kaplan-Meier analysis showed that 1-year survival rate for small-for-size graft recipients was $90.5 \%$, while the survival rate for the standard-size graft was $96.0 \%(p=0.272)$.
\end{abstract}

Conclusion: Frequency of post-op complications was comparable in both groups. The graft survival in small-for-size grafts was as good as for standard-size grafts.

Key Words: Living donor liver transplantation, GRWR, Small-for-size graft, Standard-size graft.

How to cite this article: Dogar AW, Uddin S, Hussain A, Ullah K, Ghaffar A, Abbas SH. Small-for-Size versus Standard-Size Graft in Living Donor Liver Transplantation. J Coll Physicians Surg Pak 2022; 32(03):293-297.

\section{INTRODUCTION}

Liver transplantation (LT) is considered a well-established treatment nowadays for end-stage liver diseases. ${ }^{1}$ In the deceased donor LT, graft volume is not of concern, but the quality of the graft might be low, secondary to elderly donors or graft injury, taking place during the course of brain death, organ retrieval, and storage. Contrary to this, the graft quality is usually exceptional in living donor liver transplantation (LDLT), but low graft volume can be the cause of graft dysfunction. ${ }^{2}$ Small-for-size grafts are those having a graft-to-recipient weight ratio (GRWR) of $<0.8 \%$.

Correspondence to: Dr. Azhar Hussain, Department of Liver Transplant Unit, Pir Abdul Qadir Shah Jeelani Institute of Medical Sciences, Gambat, Sindh, Pakistan

E-mail: azharhussain0139@gmail.com

Received: July 07, 2021; Revised: November 05, 2021;

Accepted: December 29, 2021

DOI: https://doi.org/10.29271/jcpsp.2022.03.293
These grafts are considered insufficient to fulfill the recipient's metabolic demands and may lead to small-for-size syndrome (SFSS), which is characterised by the presence of any of these two i.e., coagulopathy (INR $>2$ ), hepatic encephalopathy (grade $3 / 4$ ) and hyperbilirubinemia ( $>5.8 \mathrm{mg} / \mathrm{dL}$ ) during the $1^{\text {st }}$ week post-LT, after ruling out any technical abnormality. The documented pathophysiology of SFSS is enhanced liver parenchymal injury, secondary to high portal pressure and perfusion. ${ }^{3-8}$

The standard protocol in LDLT is to use grafts having a GRWR $\geq 0.8 \%$. The supporting evidence for this cutoff value is relatively weak and based on an initial study from Asia. ${ }^{2}$ However, Tanaka et al., in their landmark study, pointed out that low GRWR leads to early graft dysfunction and poor graft survival. ${ }^{9}$ Few other authors also reported similar results. ${ }^{2-4}$

With a better understanding of the pathophysiology of SFSS over time, various technical modifications were attempted to improve the outcome of small-for-size grafts and for preventing SFSS in LDLT recipients. These modifications were inflow modulation (reducing portal pressure) and outflow modulation (con- 
sidering grafts with MHV). ${ }^{10}$ Inflow modification includes splenic artery ligation, splenectomy, splenorenal, and hemi-portocaval shunting. ${ }^{11-13}$ Lee et al. concluded a low GRWR $<0.7$ is safe in adult LDLT recipients, having a low model for end-stage liver disease (MELD) score, and did not need any portal flow modulation. ${ }^{14}$ Furthermore, Alim et al. also reported that a low GRWR up to $0.6 \%$ might be safe in LDLT recipients with a MELD score of $<20$, donor age of $<45$ years, and grafts with minimal steatosis. ${ }^{15}$ Till date, the lowest successful GRWR reported in liver recipients is between $0.40 \%$ and $0.46 \% .{ }^{16}$

From a recipient perspective, the outcome of recipients with a low GRWR is unclear. Further literature and evidence are required to support the comparable outcome of small-for-size grafts as the utilisation of small-for-size grafts would increase the donors' pool in LDLT. This study aimed to compare the outcome of small-for-size grafts versus standard-size grafts regarding the frequency of postoperative complications, early graft dysfunction, and 1-year survival.

\section{METHODOLOGY}

This single-center retrospective cohort study was conducted at the Liver Transplant Department, Pir Abdul Qadir Shah Jeelani Institute of Medical Sciences. In 14 months duration, 147 recipients underwent LDLT from $1^{\text {st }}$ March 2019 to $31^{\text {st }}$ April 2020. These 147 recipients' data were analysed retrospectively. Data were collected from patients' charts. For study purposes, recipients were divided into two groups: small-for-size grafts (GRWR $<0.8 \%$ ) and standard-size grafts (GRWR $\geq 0.8 \%$ ). Various parameters, including recipients' demographics, graft characteristics, operative parameters, postoperative labs and complications, and graft survival were compared between both groups.

The donor selection criteria were as already published. ${ }^{17}$ The recipient liver transplant listing criteria include patients with child-turcotte-pugh C, MELD score of $\geq 15$, and patients with hepatocellular carcinoma (HCC) having tumor burden within Milan criteria. The recipients' upper age limit was 65 years. All the patients in this study received right lobe grafts with or without middle hepatic vein (MHV) reconstruction. Pediatric age recipients who received left lobed grafts, recipients whose indication of the transplant was acute liver failure/acute on chronic failure, those who received jump graft, or were re-transplanted were excluded from the study.

Future liver remnant (FLR) $>30 \%$ with optimal segment IV venous drainage was made sure in all donors. Donor hepatic parenchymal transection was carried with a water-jet dissector or ultrasonic surgical aspirator without inflow occlusion. The explanted graft weight measurement was done with a digital weight machine. The graft was then implanted with the piggyback technique. The right hepatic vein (RHV) anastomosis was done with the recipient RHV with a continuous non-absorbable $4 / 0$ monofilament suture. The portal vein anastomosis was also done in an end-to-end fashion with a running non-absorbable 5/0 monofilament suture. Graft perfusion was done after portal vein reconstruction. Then graft hepatic artery was anastomosed end-to-end to the recipient hepatic artery primarily, with non-absorbable $8 / 0$ interrupted sutures under 3.5 magnifying loupes. Biliary duct to duct anastomosis was performed with $5 / 0$ sutures interrupted fashion. Routine portal flow pressure measurement was not done but only in cases with SFSG portal pressure were measured, and pressure $>20 \mathrm{~mm}$ of $\mathrm{Hg}$ was set as the cutoff for portal flow modulation. However, none of the recipients underwent portal venous inflow modulation. Intraoperative doppler ultrasonography was done for hepatic arterial and portal vein flow and velocity and outflow assessment. Standard immune-suppressants included tacrolimus, while steroids were administered only for the first three months. The targeted tacrolimus level kept was 8 to $12 \mathrm{ng} / \mathrm{mL}$. All the recipients had a minimum follow-up of one year.

Data were analysed using SPSS version 25 . The arithmetic means with standard deviations were calculated for the quantitative variables, and percentages were calculated for qualitative variables. Qualitative variables were compared between the two groups using the Chi-Square test. At the same time, an independent sample T-test was used to compare quantitative variables like mean hospital stay duration, bilirubin, ALT and AST levels, and INR value. Kaplan-Maier survival analysis was done to calculate 1-year survival of patients in two groups, and a $95 \%$ confidence interval was calculated. A p-value less than 0.05 was considered statistically significant.

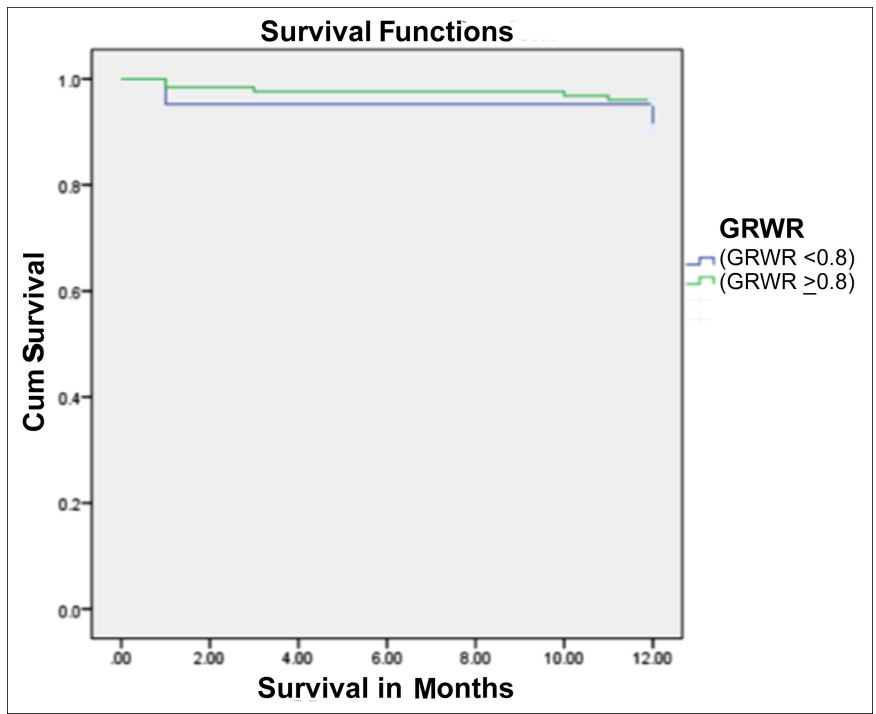

Figure 1: Kaplan-Meier curve showing 12-months survival for small-size grafts (GRWR $<0.8 \%$ ) vs. standard-size grafts (GRWR $\geq 0.8 \%$ ).

\section{RESULTS}

Out of 147, 21 recipients' grafts were found to be small-for-size. Mean age in small-for-size group and standard-size grafts group was $44.29 \pm 6.36$ years and $39.51 \pm 12.67$ years, respectively. Mean GRWR in small-for-size group and standard-size group was $0.73 \pm 0.4(0.63-0.79)$ and $0.93 \pm 0.82(0.81-3.0)$, respectively.

The most common indication of liver transplantation was hepatitis $B$ in both groups. A statistically significant difference was found while comparing body mass index $(p<0.001)$ and 
diabetes mellitus ( $p=0.001$ ) between both study groups. Mean BMl in small-for-size grafts was $27.75 \pm 3.55 \mathrm{Kg} / \mathrm{m}^{2}$ and $22.19 \pm$ $4.26 \mathrm{~kg} / \mathrm{m}^{2}$ in standard-size grafts $(p=<0.001)$. All other demographics and preoperative parameters of both groups' recipients were comparable ( $p>0.05$, Table I).

Table I: Comparison of baseline characteristics between both groups, small-for-size grafts (GRWR $<0.8 \%$ ) vs. standard-size grafts (GRWR $\geq 0.8 \%$ ).

\begin{tabular}{|c|c|c|c|}
\hline Parameters & $\begin{array}{c}\text { Small-size-grafts } \\
\text { (GRWR }<0.8 \% \text { ) } \\
\mathbf{N}=\mathbf{2 1}\end{array}$ & $\begin{array}{c}\text { Standard-size grafts } \\
\text { (GRWR } \geq 0.8 \% \text { ) } \\
\mathbf{N}=\mathbf{1 2 6}\end{array}$ & p-value \\
\hline Recipient mean age (years) & $44.29 \pm 6.36$ & $39.51 \pm 12.67$ & 0.093 \\
\hline Mean BMI $\left(\mathrm{Kg} / \mathrm{m}^{2}\right)$ & $27.75 \pm 3.55$ & $22.19 \pm 4.26$ & $<0.001$ \\
\hline $\begin{array}{l}\text { Recipient Gender } \\
\text { Male } \\
\text { Female }\end{array}$ & $\begin{array}{c}19(90.47 \%) \\
2(9.52 \%)\end{array}$ & $\begin{array}{c}112(88.89 \%) \\
14(11.12 \%)\end{array}$ & 0.829 \\
\hline $\begin{array}{l}\text { Etiology } \\
\text { HBV } \\
\text { PSC } \\
\text { BCS } \\
\text { PFIC } \\
\text { HBV\&HDV } \\
\text { HCV } \\
\text { HBV\&HCV } \\
\text { Cryptogenic } \\
\text { Wilsons's disease } \\
\text { NASH }\end{array}$ & $\begin{array}{c}9(42.85 \%) \\
1(4.76 \%) \\
0 \\
0 \\
4(19.04 \%) \\
6(28.57 \%) \\
0 \\
1(4.76 \%) \\
0 \\
0 \\
\end{array}$ & $\begin{array}{c}45(35.71 \%) \\
0 \\
5(3.96 \%) \\
2(1.58 \%) \\
39(30.95 \%) \\
20(15.87 \%) \\
5(3.96 \%) \\
6(4.76 \%) \\
3(2.38 \%) \\
1(0.79 \%)\end{array}$ & 0.247 \\
\hline $\mathrm{HCC}$ & $4(19.04 \%)$ & $19(15.07 \%)$ & 0.643 \\
\hline DM & $4(19.04 \%)$ & $3(2.38 \%)$ & 0.001 \\
\hline HTN & 0 & $1(0.79 \%)$ & 0.682 \\
\hline $\begin{array}{l}\text { Child score } \\
\text { Class A } \\
\text { Class B } \\
\text { Class C }\end{array}$ & $\begin{array}{c}0 \\
4 \\
17\end{array}$ & $\begin{array}{c}4 \\
27 \\
95\end{array}$ & 0.674 \\
\hline Mean MELD score & $19.33+3.56$ & $18.56+5.14$ & 0.524 \\
\hline Donor Mean Age (years) & $24.33+7.34$ & $23.66 \pm 5.85$ & 0.695 \\
\hline Donor Mean BMI $\left(\mathrm{kg} / \mathrm{m}^{2)}\right.$ & $21.22+3.21$ & $20.85 \pm 2.89$ & 0.591 \\
\hline Donor Mean LAl & $5.42 \pm 1.36$ & $2.36 \pm 1.99$ & $<0.001$ \\
\hline Warm ischemia time (min) & $32.62 \pm 9.30$ & $33.53 \pm 8.60$ & 0.657 \\
\hline Cold ischemia time (min) & $10.05 \pm 4.65$ & $10.62 \pm 4.35$ & 0.582 \\
\hline Operation time $(\mathrm{min})$ & $527.14 \pm 50.01$ & $531.67 \pm 58.97$ & 0.740 \\
\hline Portal Flow Modulation & 00 & 00 & \\
\hline $\begin{array}{l}\text { Venous outflow } \\
\text { Reconstruction } \\
\text { 1. MHV } \\
\text { 2. Neo-MHV } \\
\text { (Reconstructed MHV) }\end{array}$ & $\begin{array}{l}12 \\
09\end{array}$ & $\begin{array}{c}8 \\
10\end{array}$ & 0.013 \\
\hline
\end{tabular}

Table II: Comparison of $5^{\text {th }}$-day postoperative labs, drain output, encephalopathy, hospital stay, and complications between two groups.

\begin{tabular}{|l|c|c|c|}
\hline $\mathbf{5}^{\text {th }}$ POD Lab values & $\begin{array}{c}\text { Small-for-size } \\
\text { grafts } \\
\text { (GRWR }<\mathbf{0 . 8} \%)\end{array}$ & $\begin{array}{c}\text { Standard-size } \\
\text { grafts } \\
\text { (GRWR } \geq \mathbf{0 . 8} \%)\end{array}$ & p-value \\
\hline Total bilirubin (mg/dl) & $2.12 \pm 1.72$ & $2.40 \pm 2.11$ & 0.591 \\
\hline INR & $1.49 \pm 0.46$ & $1.70 \pm 1.77$ & 0.615 \\
\hline Drain output (mI/day) & $1449.44+924.01$ & $1899.78+1602.92$ & 0.248 \\
\hline Encephalopathy (grade III/IV) & 00 & 00 & - \\
\hline ALT (IU/mL) & $223.05 \pm 303.35$ & $244.03 \pm 264.61$ & 0.754 \\
\hline AST (IU/mL) & $192.68 \pm 404.83$ & $150.85 \pm 196.28$ & 0.472 \\
\hline Creatinine (mg/kg/24 h) & $0.94 \pm 0.58$ & $0.80 \pm 0.48$ & 0.269 \\
\hline Complications & & & \\
\hline $\begin{array}{l}\text { Biliary complications } \\
\text { Biliary stricture } \\
\text { Biliary leak }\end{array}$ & $4(19.05 \%)$ & $22(17.46 \%)$ & 0.767 \\
\hline Portal vein thrombosis & $2(9.52 \%)$ & $2(1.59 \%)$ & 0.127 \\
\hline Acute cellular rejection & 0 & 0 & - \\
\hline Hepatic artery thrombosis & $1(4.76 \%)$ & $2(1.59 \%)$ & 0.372 \\
\hline $\begin{array}{l}\text { INR: International normalised ratio, ALT: Alanine aminotransferase, AST: Aspartate } \\
\text { aminotransferase, }\end{array}$ & 0.379 \\
\hline
\end{tabular}

The comparison ofthe donorand grafts characteristics and operative parameters showed a significant difference in hepatic venous reconstruction $(p=0.013)$ and liver attenuation index (LAl, $p<0.001$ ) between both groups (Table I). The frequency of postoperative complications was almost comparable between both groups (Table II).

Kaplan-Meier analysis showed that the 1-year survival rate in recipients with GRWR $<0.8$ was $90.5 \%$, while the survival rate in recipients with GRWR $\geq 0.8 \%$ was $96.0 \%$ (Figure1). Mean 01-year survival time in $1^{\text {st }}$ group (SFSG; GRWR $<0.8 \%$ ) was 11.47 months (95\% Cl; 10.059-12.893), while the mean survival time in $2^{\text {nd }}$ group (Standard-size grafts; GRWR $\geq 0.8 \%$ ) was 11.73 months $(95 \% \mathrm{Cl}$; 11.452-12.008, 1-year log-rank $\mathrm{p}=0.272)$.

\section{DISCUSSION}

The increasing LDLT trend is due to decreased availability of deceased donors, especially in Asian countries. The donors have to be blood- and legally-related to the recipient to be eligible for donation. ${ }^{18}$ The lower GRWR $(<0.8 \%)$ scenario in adult LDLT often happens unintentionally due to unavailability of a suitable donor, as sometimes a donor with a borderline graft volume is considered for donation. Moreover, due to the overestimation of graft volume by CT volumetric software, the actual GRWR comes to $<0.8 \%$ after explantation. ${ }^{10}$ Usually, we avoid borderline donors, but that's not always possible.

In this study, the mean BMI of small-size grafts recipients was $27.75 \pm 3.55 \mathrm{Kg} / \mathrm{m}^{2}$, while the mean BMI in the standard-size grafts was $22.19 \pm 4.26 \mathrm{Kg} / \mathrm{m}^{2}$. The majority of these overweight recipients resulted in small-for-size grafts. This higher BMI was also recorded by Agarwal et al. in their study, and they also reported that grafts in higher BMI recipients in LDLT become small-for-size. ${ }^{19}$

Smaller graft volume may have a role in SFSS development, but it may not be the only solo factor. SFSS is considered to have a multifactorial pathophysiology. ${ }^{19}$ There can be many potential reasons for the comparable outcome of small-for-size grafts in this study. The authors took out the majority of small-for-size grafts with complete or partial middle hepatic vein (Neo-MHV) to preventanteriorsectorcongestion. Hence, functionally excellent grafts were implanted in all of these recipients. While comparing grafts with MHV and neo-MHV reconstruction, both groups showed significant differences $(p=0.013)$. The authors reconstructed any of the MHV tributaries (segments V and VIII) having a good backbench flow. Inferior hepatic veins were also reconstructed and anastomosed with IVC routinely. Many other authors had also reported that good venous outflow reconstruction is very important for implanting fully functional graft, as it prevents anterior segment congestion. . $^{10,19}$

Secondly, all the donors had age $<40$ years with no comorbidities per the protocol with a good LAl. Literature review revealed that donors with the age of $<45$ years, having minimal steatosis, yield good outcomes in small-for-size grafts. ${ }^{15}$

The mean MELD score of both groups of recipients at the study centre was less than $<20$. Alim et al. also reported that small-for-size grafts in recipients with MELD score of $<20$ results in a good outcome and a comparable survival to standard-size grafts. This had been shown by another study as well. ${ }^{15}$ More- 
over, the graft warm and cold ischemia times were much lower than reported literature. ${ }^{19} \mathrm{All}$ the above factors might be responsible for the comparable outcome in small-for-size grafts in this study.

Few studies have recommended portal flow modulation techniques like splenectomy, splenic artery ligation, splenorenal or portocaval shunting to reduce portal vein pressure and prevent SFSS. ${ }^{11-13,20}$ The notable feature of this study was that no portal flow modulation procedures were performed in the recipients, as the authors did not record high portal flow pressure ( $>20 \mathrm{~mm}$ $\mathrm{Hg}$ ). Few other studies also concluded that portal flow modulation in small-for-size grafts is not necessary. Lee et al. also reported that small right lobe grafts are safe without portal flow modulation, as the majority of their patients did not develop SFSS. ${ }^{14}$ Agarwal et al. also experienced that portal flow modulation is not needed in all low GRWR obese recipients. ${ }^{19}$

Regarding postoperative laboratory parameters and complications, i.e., vascular and biliary complications and acute cellular rejection incidence were comparable in both groups. Any of the recipients did not develop SFSS. Disparate to this study, few authors have reported a higher incidence of hepatic artery thrombosis with small-for-size grafts, resulting in increased graft loss and mortality. ${ }^{7}$ The authors did not experience such thing. Multiple studies have also reported a comparable rate of postoperative complications. ${ }^{19,21-23}$

The present data showed that smaller grafts did not have an inferior outcome compared to standard-size grafts. Kiuchi et al. reported that GRWR $<0.8 \%$ are extra small and result in early graft dysfunction and poor graft survival. ${ }^{2}$ Fan et al. also showed the inferior outcome of small-for-size grafts. ${ }^{24}$ The outcome of these initial studies was contradictory to this study. The results of these studies were concluded from early LDLT experiences with various confounding variables like mixed right and left lobe grafts inclusion, pediatric age recipients, and with no focus on venous outflow reconstruction. ${ }^{2}$ However, studies by Nishizaki etal. and Shimada etal. reported good outcomes with the small-for-size grafts. ${ }^{19,25}$ Selzneret et al. compared post-LDLT outcomes ofLDLTrecipients withsmall-for-size grafts, standard-size grafts, and those who underwent DDLT. They found no difference in terms of normalisation of serum bilirubin and INR. The recipient overall survival rates were also similar in all these three groups. ${ }^{8}$ Similar results have been shown by another study in which obese patients received small-for-size grafts. ${ }^{18}$ In this study, the 1-year survival rate in recipients with the standard-size grafts was slightly higher $(96 \%)$ than the survival rate in recipients with small-for-size grafts $(90.5 \%)$, but was statically not significant.

This study showed a good outcome of small-for-size grafts in terms of survival rate and comparable postoperative complications. Proper planning and strategy can prevent early graft dysfunction and improve survival in cases with GRWR $<0.8 \%$. This will increase the potential donor pool in LDLT centres, where they constantly struggle for potential donors.
The limitations of this study are single-centre, retrospective nature, and a relatively smaller sample size. The authors recommend further studies from established centres to validate and augment these results.

\section{CONCLUSION}

This study showed that the outcome of small-for-size grafts is comparable with the standard- size grafts in terms of incidence of SFSS, postoperative complications, and 1-year graft survival. Key factors to have a good outcome in such cases are good donor selection in terms of young age and good LAl, low MELD scores recipients, and a good outflow reconstruction in the form of MHV or Neo-MHV.

\section{ETHICALAPPROVAL:}

This study was approved by the Hospital's Institutional Ethical Review Board (IERB) and an Ethical Approval letter was issued to the authors.

\section{PATIENTS' CONSENT:}

Informed and written consents were obtained from the patients to publish the data.

\section{CONFLICT OF INTEREST:}

The authors declared no conflict of interest.

\section{AUTHORS' CONTRIBUTION:}

AWD: Designed the study and revised it.

SU: Collected and arranged data.

$\mathrm{AH}$ : Contributed in statistical analysis of data and writing manuscript. KU, SHA: Compiled the data.

AG: Designed the study and did revision of the article.

\section{REFERENCES}

1. Botha JF, Langnas AN, Campos BD, Grant WJ, Freise CE, Ascher NL, et al. Left lobe adult-to-adult living donor liver transplantation: Small grafts and hemi portocaval shunts in the prevention of small-for-size syndrome. Liver Transpl 2010; 16(5): 649-57. doi/abs/10.1002/ It.22043.

2. Kiuchi T, Kasahara M, Uryuhara K, Inomata Y, Uemoto S, Asonuma $\mathrm{K}$, et al. Impact of graft size mismatching on graft prognosis in liver transplantation from living donors. Transplantation 1999; 67(2):321-7. doi: 10. 1097/00007890-19990 1270-00024.

3. Dahm F, Georgiev P, Clavien PA. Small-for-size syndrome after partial liver transplantation: definition, mechanisms of disease and clinical implications. Am J Transplant 2005; 5(11):2605-10. doi.org/10.1111/j.1600-6143.2005.01081.x.

4. Tanaka K, Ogura Y. Small-for-size graft and 'small-forsize syndrome' in living donor liver transplantation. Yonsei Med J 2004; 45(6):1089-94. doi: 10.3349/ymj. 2004.45.6.1089.

5. Soejima $Y$, Taketomi A, Yoshizumi T, Uchiyama $H$, Harada $\mathrm{N}$, ljichi $\mathrm{H}$, et al. Feasibility of left lobe living donor liver transplantation between adults: An 8-year, single centre experience of 107 cases. Am J Transplant 
2006; 6(5 Pt 1):1004-11. (doi.org/10. 1111/j.16006143.2006.01284.x).

6. Hill MJ, Hughes M, Jie T, Cohen M, Lake J, Payne WD, et al. Graft weight/recipient weight ratio: how well does it predict outcome after partial liver transplants? Liver Transp/ 2009; 15(9):1056-62. doi.org/10.1002/lt.21846.

7. Ikegami T, Shirabe K, Yoshizumi T, Aishima S, Taketomi YA, Soejima $Y$, et al. Primary graft dysfunction after living donor liver transplantation is characterised by delayed functional hyper-bilirubinaemia. Am J Transplant 2012; 12(7): 1886-97. doi.org/10.1111/j.1600-6143. 2012.04052.x.

8. Selzner M, Kashfi A, Cattral MS, Selzner N, Greig PD, Lilly $L$, et al. A graft to body weight ratio less than 0.8 does not exclude adult-to-adult right-lobe living donor liver transplantation. Liver Transpl 2009; 15(12):1776-82. doi.org/10.1002/lt.21955.

9. Kiuchi T, Tanaka K, Ito T, Oike F, Ogura Y, Fujimoto $Y$, et al. small-for-size graft in living donor liver transplantation: How far should we go? Liver Transpl 2003; 9(9):S29-S30. doi.org/10.1053/jlts. 2003.50198.

10. Yagi S, Uemoto S. Small-for-size syndrome in living donor liver transplantation. Hepatobiliary Pancreat Dis Int 2012; 11(6):570-6. doi.org/10.1016/S1499-3872 (12)60227-6.

11. Umeda Y, Yagi T, Sadamori H, Matsukawa H, Matsuda H, Shinoura S, et al. Effects of prophylactic splenic artery modulation on portal overperfusion and liver regeneration in small-for-size graft. Transplantation 2008; 86(5):673-80. doi: 10.1097/ TP.0b013e318 $181 \mathrm{e} 02 \mathrm{~d}$.

12. Ogura $Y$, Hori T, El Moghazy WM, Yoshizawa A, Oike F, Mori $A$, et al. Portal pressure $<15 \mathrm{mmHg}$ is a key for successful adult living donor liver transplantation utilizing smaller grafts than before. Liver Transp/ 2010; 16(6):71-28. doi.org/10.1002/lt.22059.

13. Troisi R, Ricciardi S, Smeets P, Petrovic M, Maele GV, Colle I, et al. Effects of hemi-portocaval shunts for inflow modulation on the outcome of small-for-size grafts in living donor liver transplantation. Am J Transplant 2005; 5(6):1397-404. doi.org/10. 1111/j. 1600-6143. 2005.00 850.x.

14. Lee SD, Kim SH, Kim YK, Lee SA, Park SJ. Graft-torecipient weight ratio lower to $0.7 \%$ is safe without portal pressure modulation in right-lobe living donor liver transplantation with favorable conditions. Hepatobiliary Pancreat Dis Int 2014; 13(1):18-24. doi.org/10.1016/S1499-3872(14)60002-3.
15. Alim A, Erdogan Y, Yuzer Y, Tokat Y, Oezcelik A. Graft-to recipient weight ratio threshold adjusted to the model for end-stage liver disease score for living donor liver transplantation. Liver Transpl 2016; 22(12):1643-8. doi: 10.1002/lt.24523.

16. Lee SG. A complete treatment of adult living donor liver transplantation: A review of surgical technique and current challenges to expand indication of patients. Am J Transplant 2015; 15(1):17-38. doi: 10.1111/ajt.12907.

17. Ullah K, Dogar AW, Uddin S, Hasnain S, Ahmad B, Ghaffar A. Frequency and outcome of hepatic arterial thrombosis in recipients of living donor liver transplantation. J Coll Physicians Surg Pak 2021; 31(8):897-902. doi: 10.29271/jcpsp.2021.08.897.

18. Lo CM. Deceased donation in Asia: Challenges and opportunities. Liver Transpl 2012; 18(2): S5S7. doi.org/10.1002/lt.23545.

19. Agarwal S, Goyal N, Nayeem M, Pareek S, Gupta S. Living donor liver transplantation in patients weighing $\geq 100 \mathrm{~kg}$ : Low graft weight and obesity do not impact outcomes. Liver Transpl 2017; 23(1):35-42. doi: 10.1002/lt.24653.

20. Nishizaki T, Ikegami T, Hiroshige S, Hashimoto K, Uchiyama $\mathrm{H}$, Yoshizumi $\mathrm{T}$, et al. small graft for living donor liver transplantation. Ann Surg 2001; 233:575-80. doi: 10.1097/00000658-200 104000-00014.

21. Ishizaki Y, Kawasaki S, Sugo H, Yoshimoto J, Fujiwara N, Imamura H. Left lobe adult-to-adult living donor liver transplantation: Should portal inflow modulation be added? LiverTranspl 2012; 18(3): 305-14. doi.org/10. 1002/lt. 22440.

22. Lei JY, Yan LN, Li B, Wen TF, Wang WT, Xu MQ, et al. Graft size alone should not affect donors selection and be used to predict the prognosis of recipients after living donor liver transplantation. Hepatogastroenterol 2012; 59(113):224-7. doi: 10.5754/hge11035.

23. Moon JI, Kwon CHD, Joh JW, Jung GO, Choi GS, Park JB, et al. Safety of small-for-size grafts inadult-to-adult living donor liver transplantation using the right lobe. Liver Transp/ 2010; 16(7):864-9. doi.org/10.1002/lt.22094.

24. Fan ST, Lo CM, Liu CL, Yong BH, Wong J. Determinants of hospital mortality of adult recipients of right lobe live donor liver transplantation. Ann Surg 2003; 238(6): 864-9. doi: 10.1097/01.sla.000 0098618. 11382.77.

25. Shimada M, Ijichi H, Yonemura Y, Harada N, Shiotani S, Ninomiya $M$, et al. Is graft size a major risk factor in livingd onor adult liver transplantation? Transpl Int 2004; 17(6):310-6. doi.org/10.1111/j.1432-2277. 2004.tb0 0448.x. 